Portland State University

PDXScholar

Summer 8-2-2018

\title{
Inclusion and Assimilation: Including Change in the Workplace
}

Marisa Jean Miller

Portland State University

Follow this and additional works at: https://pdxscholar.library.pdx.edu/open_access_etds

Part of the Communication Commons Let us know how access to this document benefits you.

Recommended Citation

Miller, Marisa Jean, "Inclusion and Assimilation: Including Change in the Workplace" (2018). Dissertations and Theses. Paper 4539.

https://doi.org/10.15760/etd.6424

This Thesis is brought to you for free and open access. It has been accepted for inclusion in Dissertations and Theses by an authorized administrator of PDXScholar. Please contact us if we can make this document more accessible: pdxscholar@pdx.edu. 
Inclusion and Assimilation: Including Change in the Workplace

\author{
by
}

Marisa Jean Miller

A thesis submitted in partial fulfillment of the requirements for the degree of

\author{
Master of Science \\ in \\ Communication
}

Thesis Committee:

Brian Manata, Chair

Lauren Frank

Erin Spottswood

\author{
Portland State University \\ 2018
}




\begin{abstract}
Organizational assimilation is an ongoing and dynamic relationship between organization and individual member, where employees learn the expected norms of the organization and feel that they are able to attempt to make a change to the organization. Organizational members rely on social interactions within the organization to acquire the necessary knowledge they need to perform their roles, as well as support to attempt changes within the organization. This study proposes that feelings of inclusion, or the perception that an employee both belongs to and is unique within an organization, may be an influential construct associated with organizational assimilation and beneficial assimilation outcomes. This study conducts quantitative analysis of survey data collected from employees at a university in the Pacific Northwest, and considers the following components of organizational assimilation, organizational knowledge and individualization, and their potential connection to inclusion in the workplace. Inclusion in the workplace is conceptualized as social inclusion and task inclusion. This study finds that organizational knowledge and individualization are positively associated with social and task inclusion. This is useful to assimilation literature, because inclusion is not often considered when studying organizational assimilation. In addition, these results indicate that inclusion in the workplace is valuable to creating a workplace where employees feel that they can invest themselves in an organization, and are free to individualize their role or attempt to make some sort of change to the organization.
\end{abstract}




\section{Acknowledgements}

There are several parties who have been integral to the completion of this thesis project. I would like to thank Dr. Brian Manata for his wisdom and guidance from the inception of this idea and throughout the execution of this project. I would also like to thank Dr. Lauren Frank and her superior wisdom and sincere interest in this project. Without her invaluable feedback, this project would not be near what it has become. Dr. Erin Spottswood provided encouragement and support that cannot be put into words, and has been central to my development as a student and scholar. There are several other members of the Communication Department, both faculty and staff who have been supportive, informative, and invested in this project. I would also like to thank all of the members of my cohort, without whom I would not have been able to complete this program. Finally, I would like to acknowledge the unwavering support of my husband, Steven Miller. Without his constant encouragement, attempted interest in this project, and late night food deliveries, this would not have been possible. 
Table of Contents

Abstract $\quad$ i

Acknowledgements

List of Tables

iv

List of Figures

V

Chapter 1

Introduction

1

Chapter 2

Review of the Literature

3

Chapter 3

Methods

Chapter 4

Results

Chapter 5

Discussion

References 
List of Tables

Table 1

Variable Means, Standard Deviations, Reliability Coefficients, and Correlations 18

Table 2

Confidence Intervals 
List of Figures

Figure 1

Conceptual Model of Hypotheses and Research Question 
Chapter 1 - Introduction

Organizational members who are assimilated are valuable employees to an organization, as these employees behave according to the expectations and normative social behaviors of the organization (Myers \& McPhee, 2006). Moreover, assimilation is valuable to employees, as it allows them to influence the organization by making changes to their specific role or a process within the organization (Jablin, 2001; Myers \& Oetzel, 2003). Ultimately, this process allows for a more fruitful relationship between employee and organization (Myers, 2009). Indeed, successful assimilation is associated with higher job satisfaction, greater organizational identification, and intention to remain with the organization (Myers \& Oetzel, 2003).

In addition to the practical benefits that accompany assimilation, there are also more tangible benefits. Employee turnover is costly to organizations in both time and resources. Organizations dedicate time to exit interviews for departing candidates, recruiting and selecting new members, training new members, and there is productivity that is lost while new members are acclimated to their new positions (Tracey \& Hinkin, 2008). Lost productivity is often reported as the highest cost due to employee turnover. In a study of employee turnover in the hospitality industry, for example, Tracey and Hinkin (2008) discovered that costs to replace a productive employee can be "in excess of $\$ 12,000$ " (p. 24) for lower and entry-level employees. Similarly, a training industry report indicates that on average, organizations in the U.S. spent $\$ 1,075$ per new employee in 2017, and on average "employees received 47.6 hours of training per year" (Training, 2017 , p. 23) in 2017. Turnover can also be costly to companies in resources dedicated to recruitment, training, as well as lost productivity. Consequently, attempting to assimilate 
employees is valuable to the employee as they are generally more satisfied with their role (Myers \& Oetzel, 2003), and is also valuable to organizations in that they are better able to reduce the prohibitive costs associated with employee turnover.

To date, research indicates that social interaction is a vital component that facilitates assimilation (Cranmer, Goldman, \& Booth-Butterfield, 2017; Gailliard et al., 2010; Kramer \& Miller, 2014; Levine \& Moreland, 2006; Morrison, 2002; Myers \& Oetzel, 2003; Ostroff \& Kozlowski, 1992; Scott \& Myers, 2010). However, how social interaction facilitates assimilation outcomes remains unclear (Manata, Miller, DeAngelis, \& Paik, 2016). In addressing this lacuna, this study investigates inclusion through social interaction as a possible facilitator of assimilation for organizational members. Specifically, this study first reviews components of assimilation as well as different types of inclusion that occur in the workplace. Secondly, employees of a large university in the Pacific Northwest are surveyed in order to investigate the extent to which inclusion and assimilation are associated. Finally, a discussion is offered, detailing the current study's findings, which suggest that inclusion and organizational assimilation are linked. Additionally, study limitations and future research directions are both considered and entertained. 
Chapter 2 - Review of the Literature

Organizational assimilation is an ongoing process of one's integration into the organizational culture (Jablin, 2001). Specifically, successful assimilation promotes the facilitation of organizational membership, which culminates in an employee who feels integrated within and adjusted to an organization (Gailliard, Myers, \& Seibold, 2010; Waldeck \& Myers, 2007). Indeed, as Myers (2009) notes, "When members assimilate, they become familiar with the culture and assume their roles as participating members of the organization" (p. 722).

To date, scholars contend that organizational assimilation is a function of two notable processes: socialization and newcomer individualization (Gailliard et al., 2010; Jablin, 2001). In the main, socialization is a process whereby employees learn "the ropes" of the organization (Van Maanen \& Schein, 1979, p. 211), familiarize themselves with their specific role, and learn the language, history, goals and values of the organization (Chao, O’Leary-Kelly, Wolf, Klein, \& Gardner, 1994). Knowledge that is acquired through socialization is valuable in helping employees to perform their specific role. Specifically, socialization provides members with the organizational knowledge they need to exist within an organization and reduce anxiety that may be associated with uncertainty about their organizational environment (Morrison, 1993; Waldeck \& Myers, 2007). Moreover, well socialized individuals are more satisfied, more involved and adaptable, and have a better sense of personal identity than those who are less well socialized (Chao et al., 1994).

According to Myers and Oetzel (2003), two components of organizational knowledge that are required for successful assimilation are acculturation and job 
competency. Respectively, Myers and Oetzel indicate that newcomer acculturation occurs through "learning and accepting the culture" (p. 443). Notably, this includes learning the cultural norms of how to behave in the workplace. Additionally, Myers and Oetzel recognize that job competency indicates that members know how to do their jobs, and do them well. Of note, other authors have made similar arguments. Morrison (1993), for example, indicates that, initially, newcomers seek social feedback from their peers, but over time, employees shift their focus to feedback regarding their performance and their specific role from supervisors. Similarly, Ostroff and Kozlowski (1992) indicate that newcomers differentiate between information about the organization, such as values, goals, and culture, and information regarding mastering their specific task and navigating their group dynamics. Thus, upon entering an organization, assimilation is generally achieved by being socialized to and learning the organizational culture, as well as learning how to perform one's job (Myers \& Oetzel, 2003).

In addition to being socialized, organizational members individualize their roles by becoming competent at performing their required tasks and by attempting to alter or change their specific role (Miller, Johnson, Hart, \& Peterson, 1999). Attempts to influence how they enact their role, its purpose, or how they will be evaluated, are ways that individuals attempt to shape their role to meet their individual needs, abilities, and wishes (Jablin, 2001; Miller et al., 1999; Van Maanen \& Schein, 1979). Similar to successful socialization, role negotiation is essential to employee adjustment and innovation, as role negotiation allows individuals to familiarize themselves with their role 
and its expectations, as well as attempt to alter it in ways that lead to personal and professional growth (Miller et al., 1999).

Individualization likely involves a combination of members' involvement, as well as their specific attempts to negotiate their role. Specifically, individualization is a balance between becoming involved with the group, as well as being a unique member of that group (Jablin, 2001; Myers \& Oetzel, 2003). Myers and Oetzel (2003), for instance, indicate that organizational members monitor and assess the level of involvement of other members in order to evaluate others' assimilation into the organization. Moreover, Myers and McPhee (2006) note that members' involvement is influenced by their desire to become involved, which predicts both organizational commitment and acceptance. In other words, these members' involvement was influenced by their proactive desire to become involved with the group.

In addition to becoming involved with the group, individuals engage in role negotiation. Specific role negotiation attempts serve as evidence that an individual is making changes to the organization, often by performing their role in a new way that is more suited to the individual (Gailliard et al., 2010). This is an effort on the part of organizational members to adjust their role to suit some sort of need or unique skill that they offer (Jablin, 2001). Role negotiation gives individuals a chance to make changes to their role in practical ways, such as modifying processes in order to make them more efficient, and it also gives members a chance to employ their unique skills in ways that benefit themselves and the organization (Jablin, 2001). 
In sum, organizational assimilation is the result of attempts made by the organization to socialize employees, as well as attempts made by employees to individualize their specific role (Jablin, 2001; Waldeck \& Myers, 2007). Ultimately, understanding the process of assimilation is important because successful assimilation results in individuals who feel integrated with the organization (Gailliard et al., 2010; Jablin, 2001; Waldeck \& Myers, 2007) and feel that they are valuable members of the organization (Myers \& Oetzel, 2003). Moreover, assimilation allows members to identify and conform to the norms and expected behaviors of an organization, feel like an involved and contributing member, as well as define their roles and attempt to influence their organization (Waldeck \& Myers, 2007). Indeed, assimilated individuals are valuable to organizations, as assimilation outcomes include lower turnover rates, greater job satisfaction, more organizational identification, and a favorable organizational culture (Myers \& Oetzel, 2003).

Despite the known benefits of successful assimilation, more research is needed to understand precisely how individuals assimilate to an organization (Manata et al., 2016; Waldeck \& Myers, 2007). Specifically, although it is generally accepted that successful assimilation occurs as a result of interactions with other organizational members (Cranmer et al., 2017; Gailliard et al., 2010; Kramer \& Miller, 2014; Levine \& Moreland, 2006; Morrison, 2002; Myers \& Oetzel, 2003; Ostroff \& Kozlowski, 1992; Scott \& Myers, 2010), little is known about how this occurs (Manata et al., 2016). Zorn and Gregory (2005), for example, call for additional research that investigates how coworker interactions influence work experiences and sense making, especially as they occur 
within the context of organizational assimilation. Thus, in an attempt to address this general call, the current study proposes to investigate relationships and interactions between employees, their peers, and supervisors to discover how these interactions contribute to newcomer assimilation outcomes (e.g., organizational knowledge, role negotiation).

In the main, coworkers constitute a critical source of information for the newcomer. Specifically, when new members arrive at an organization they look to other organizational members to provide the information they need, either by inquiring directly, or by employing other, more covert methods such as observation or surveillance (Morrison, 1993). Moreover, in addition to providing tactical and organizational information regarding language, history, and politics, existing organizational members also provide social feedback (Morrison, 1993). Notably, social feedback includes information regarding non-task behaviors (Morrison, 1993) and can contribute to satisfying work relationships (Chao et al., 1994). In addition, social relationships can provide support and a sense of belonging (Morrison, 2002). That is to say, social relationships facilitate the extent to which one feels included.

Inclusion is the "degree to which an employee perceives that he or she is an esteemed member of the workgroup through experiencing treatment that satisfies his or her needs for belongingness and uniqueness" (Shore et al., 2011, p. 1265). Inclusion differs from involvement, as involvement results from an individual's desire and proactive behaviors to involve themselves in the work group. In contrast, Shore et al. note that perceptions of inclusion are a balance between feeling as if one belongs to the group, 
but is also unique within the group. This uniqueness is important because it allows individuals to feel that they are valuable and not easily replaceable by the group (i.e., that they are included). Notably, this resembles Jablin's (2001) notion of individualization, in that employees deliberately negotiate their roles in order to reflect their unique needs or abilities. Similarly, Mor-Barak and Cherin (1998) consider perceptions of inclusion to be the degree to which individuals feel a part of critical organizational processes through "involvement in work groups, and ability to influence the decision making process" (p. 48). Stated differently, Mor-Barak and Cherin contend that feelings of inclusion can occur in terms of both social and task dynamics.

Social inclusion is the degree to which members feel involved and a part of the social interactions and dynamics in their work groups, such as informal discussions, access to information, or feeling listened to by their peers. In their study to determine the dimensions of socialization, Chao et al. (1994) captured feelings of friendship and inclusion in their measure of "people." By feeling included socially, members may have access to the organizational information that they need to feel as if they belong to their group and become proficient at their specific role (Morrison, 1993). In addition, feeling included socially may allow members to feel that, should they attempt to make changes to their role or the organization in some way, these changes would be accepted by their peers. Indeed, satisfying social relationships can facilitate socialization and assimilation (Chao et al., 1994), as assimilation occurs by interacting with others (Gailliard et al., 2010). Consequently, it is posited that feeling socially included facilitates the extent to which an individual feels assimilated. 
Alternatively, task inclusion is the degree to which members feel they are consulted or involved in influencing the specific tasks they perform. Specifically, organizational members feel integrated when their supervisors include them in the decision-making process (Ding \& Shen, 2017). This ability to influence decision-making is referred to as participatory decision-making. Participatory decision-making can be evaluated in terms of employees' involvement in decision-making (Cotton, Vollrath, Froggatt, Lengnick-Hall, \& Jennings, 1988) as well as being informed about their job or task. Research has shown that participatory decision-making can have positive effects on productivity and performance, perceived influence, and involvement (Cotton et al., 1988). Individuals perceive that they hold a high insider status when participatory decision-making is high (Ding \& Shen, 2017). Miller and Monge (1986) also note that participation in decision-making is quite influential for job satisfaction and productivity when organizational members perceive there to be a participative climate. It is likely that if employees perceive they are included in decision-making processes and hold a high insider status, they may also feel free to make changes to their role or the organization at large. Additionally, participatory decision-making includes providing employees with necessary information needed to influence decisions (Mor-Barak \& Cherin, 1998). Thus, task inclusion may facilitate assimilation by providing employees with necessary organizational knowledge, and opportunities to make changes to their role or the organization. 
Figure 1. Conceptual Model of Hypotheses and Research Question

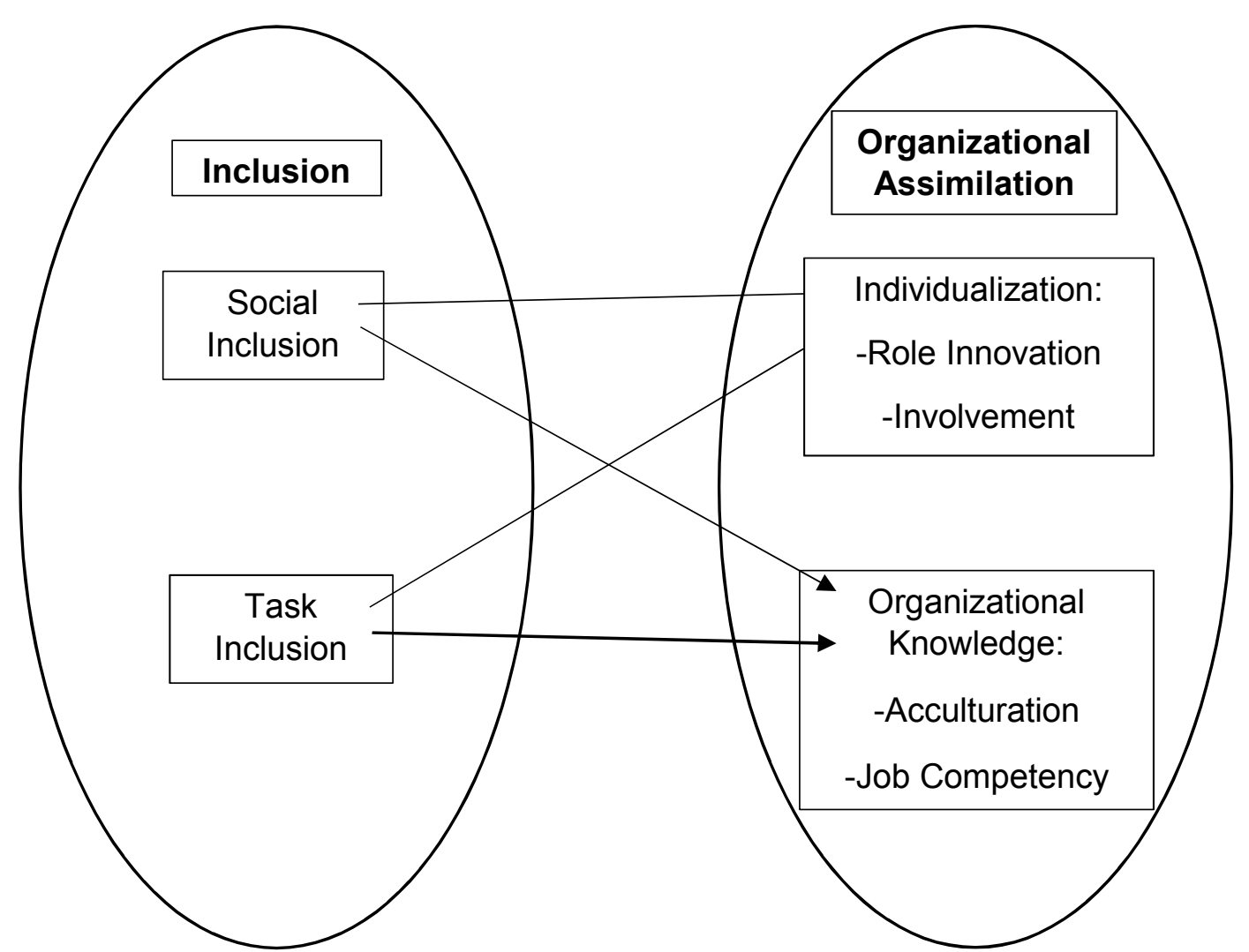

In sum, it is predicted that members who feel included overall (i.e. both social and task inclusion) are more likely to become proficient at their job and acculturated to the organization. Members are also likely to feel comfortable when attempting to affect some sort of change within the organization, such as becoming involved and innovating their role. Figure 1 illustrates the potential relationships between these constructs. In the interest of exploring the extent to which these expectations are correct, the following are offered:

H1: Social inclusion will be associated positively with a) organizational knowledge (i.e. acculturation and job competency) and b) individualization (i.e. involvement and role negotiation). 
H2: Task inclusion will be associated positively with a) organizational knowledge (i.e. acculturation and job competency) and b) individualization (i.e. involvement and role negotiation).

While it is likely that both task and social inclusion influence the extent to which organizational members gain organizational knowledge and individualize their roles, it remains unclear whether social inclusion or task inclusion is a bigger predictor of these components of assimilation. Indeed, it may be that social inclusion is more vital in providing members with access to information necessary for acculturation and to become proficient at one's role. Specifically, by being included socially, individuals may be more likely to understand the social norms and expectations regarding behavior through exposure to those social norms simply because they are included in social interaction amongst other organizational members (Morrison, 1993; Myers \& McPhee, 2006). Thus, employees are privy to knowledge regarding acculturation and job proficiency through inclusion in social interactions, both formal and informal. Alternatively, it may be the case that task inclusion may provide more opportunity for individuals to have access to information necessary to proactively involve themselves in decision-making, as well as to make changes to their role as they see fit. By being included in decision-making, employees may have access to necessary information to form opinions and involve themselves in the decision-making process (Mor-Barak \& Cherin, 1998). Task inclusion may also provide necessary insight to make appropriate adjustments to their role (MorBarak \& Cherin, 1998) to increase efficiency or otherwise employ a skill they possess that has not traditionally been assigned to their role. Consequently, both task and social 
elements of inclusion may be more important to facilitating certain aspects of assimilation when comparing one to the other. As such, this study seeks to investigate:

RQ1: Is social inclusion or task inclusion a bigger predictor of a) organizational knowledge (i.e. acculturation and job competency) and/or b) individualization (i.e. involvement and role negotiation) (see figure 1)? 
Chapter 3 - Methods

\section{Sample}

This study recruited from the employee population of an urban university located in the Pacific Northwest. Participants were full and part-time employees that occupy diverse roles (i.e., office staff, faculty, graduate student employee, advising, undergraduate student employee). Of the total participants included in the study $(N=$ $251)$, there were 74 males $(29.5 \%), 151$ females $(60.2 \%)$, and 5 who identified as "other" (2.0\%). Participants who reported ethnicity self-identified as White/Caucasian $(n=187$, $74.5 \%)$, Hispanic or Latino ( $n=8,3.2 \%)$, Black or African American $(n=4,1.6 \%)$, Asian/Pacific Islander $(n=14,5.6 \%)$, and the remainder of participants reported as "other" $(n=15,6.0 \%)$. Ages ranged from 19-81 $(M=41.36, S D=12.28)$, and participants reported being an employee of the university for an average of 8 years $(S D=$ 8.60). Participants also reported having the role of faculty ( $n=94,37.5 \%)$, office staff ( $n$ $=41,16.3 \%)$, graduate student employee $(n=49,19.5 \%)$, undergraduate student employee $(n=3,1.3 \%)$, advising $(n=9,3.9 \%)$ or reported as "other" or did not specify $(n=33,13.2 \%)$.

Participants, however, were excluded from the survey if they reported that they were not currently employed by the university, and as a result of this restriction six participants were excluded from analysis. Participants were also excluded from analysis if they answered one question or less. As a result, 22 cases were excluded for no response, and 54 cases were excluded for only answering one question. The one question that was answered was purely descriptive (i.e., job role) and did not provide any additional information that could be used to investigate hypotheses. Three cases were 
excluded from analysis because they were duplicate submissions. This left a total of 251 survey participants who were included in data analysis. Additionally, analysis employed listwise deletion to address missing data. All participants consented to participating in this survey. IRB approval was obtained before data collection began, and relevant materials can be found in Appendix B.

\section{Procedure}

In soliciting responses, a digital survey link was distributed via email to university employees (e.g., faculty, office staff, and graduate student employees). This digital survey was provided to department chairs of the population of study, and was subsequently distributed to the employee population via email from department chairs. In addition, three reminder emails were sent to department chairs during the four-week data collection period (i.e., once a week). Of note, participant responses were solicited regardless of their organizational tenure (e.g., newcomers versus old-timers). Ultimately, this decision was made because organizational members move through stages of assimilation at different rates (Jablin, 2001; Myers \& Oetzel, 2003; Gailliard et al., 2010). Moreover, a common critique of the assimilation literature is that it focuses only on newcomers, despite the common contention that assimilation constitutes a lifelong process (Waldeck \& Myers, 2007). Participants were offered a chance to receive one of four $\$ 50$ electronic Amazon gift cards in exchange for their participation by entering their contact information into a separate survey that was not linked to the original survey. Results of the study findings were shared in aggregate with members of the leadership team within the college of study. 


\section{Measures}

Organizational knowledge. In order to assess different aspects of organizational knowledge, scales from Gailliard et al. (2010) were used to assess perceptions of acculturation and job competency. The survey instrument can be found in Appendix A.

To assess acculturation, participants were asked to indicate their level of agreement with the following statements, "I understand the standards of the organization," "I think I have a good idea about how this organization operates," "I know the values of my organization," and "I do not mind being asked to perform my work according to the organization's standards." Moreover, all four items were assessed with 7-point Likert scales $(1=$ strongly disagree, $7=$ strongly agree $)$. Myers and McPhee (2006) and Gailliard et al. (2010) confirmed the validity of this measure. This study reports a Cronbach alpha reliability of $\alpha=.85(M=5.37, S D=1.11)$ for acculturation.

To assess job competency, participants were asked to indicate their level of agreement with the following statements, "I can do others' jobs, if I am needed," "I have figured out efficient ways to do my work," "I think I am an expert at what I do," and "I often show others how to perform our work." All four items were assessed with 7-point Likert scales $(1=$ strongly disagree, $7=$ strongly agree $)$. Validity of this measure was confirmed by Gailliard et al. (2010) and Myers and McPhee (2006). This study reports a Cronbach alpha reliability of $\alpha=.62(M=5.42, S D=.88)$ for job competency. Admittedly, the reported reliability for this scale is low. However, this scale was used for the current study as it is included with other measures that were used from Gailliard et al.’s (2010) updated organizational assimilation index (OAI). It seemed appropriate to 
use these measures together, as they are often used in organizational research, rather than attempt to supplement a measure that did not come from Gailliard et al. (2010).

Individualization. In capturing different aspects of individualization, scales from Gailliard et al. (2010) were used to assess perceptions of involvement and role negotiation.

To assess involvement, participants were asked to indicate their level of agreement with the following statements, "I talk to my coworkers about how much I like it here," "I volunteer for duties that benefit the organization," and "I talk about how much I enjoy my work." All three items were assessed with 7-point Likert scales $(1=$ strongly disagree, 7 = strongly agree). Validity of this measure was also confirmed by Gailliard et al. (2010) and Myers and McPhee (2006). This study reports a Cronbach alpha reliability of $\alpha=.75$ $(M=4.75, S D=1.28)$ for involvement.

To assess role negotiation, participants were asked to indicate their level of agreement with the following statements, "I have helped to change the duties of my position," "I have changed some aspect of my position," and "I do this job a bit differently than my predecessor did." Moreover, all three items were assessed with 7point Likert scales $(1=$ strongly disagree, $7=$ strongly agree $)$. Validity of these measures was also confirmed by Gailliard et al. (2010) and Myers and McPhee (2006). This study reports a Cronbach alpha reliability of $\alpha=.80(M=4.99, S D=1.27)$ for role negotiation.

Social inclusion. Participants' perceptions of social inclusion were measured via the Chao et al. (1994) people scale, made up of six items. Respondents were asked to 
indicate their level of agreement $(1=$ strongly disagree, $7=$ strongly agree $)$ with the following statements, "I do not consider any of my coworkers as friends," (reverse coded) "I am usually excluded in social get togethers given by other people in my department," (reverse coded) "Within my work group, I would be easily identified as 'one of the gang'," "I am usually excluded in informal networks or gatherings of people in my department," (reverse coded) "I am pretty popular in my department," "I believe most of my coworkers like me." This study reports a Cronbach alpha reliability coefficient at $\alpha=.81(M=5.12, S D=1.00)$ for social inclusion.

Task inclusion. Task inclusion was measured via the Mor-Barak and Cherin (1998) influence in decision-making four-item scale. Respondents were asked to indicate their level of agreement $(1=$ strongly disagree, $7=$ strongly agree $)$ with statements such as "I am able to influence departmental decisions," "I am able to influence work assignment directions," "I am consulted about important project decisions," and "I have a say in the way work is performed." Mor-Barak and Cherin (1998) confirmed the validity of these measures. This study reports a Cronbach alpha reliability coefficient at $\alpha=.90$ $(M=4.58, S D=1.48)$ for task inclusion

\section{Analysis}

To investigate $\mathrm{H} 1$ and H2, data were analyzed using Pearson's $r$ as data were normally distributed. In addition, to investigate RQ1 Pearson's $r$ was also used, and confidence intervals were compared to determine differences in effect sizes. If confidence intervals overlapped, the effect sizes were not considered sufficiently distinct from one another. 
Chapter 4 - Results

All analyses were based on an initial sample size of 251. Correlation coefficients between each of the variables can be found in Table 1, as well the variables' respective means, standard deviations, and reliability coefficients.

\section{Inclusion and Organizational Knowledge}

Hypothesis 1a indicated that social inclusion would be positively associated with organizational knowledge, which was represented by acculturation and job competency measures. Correlation analysis revealed that there was a significant positive relationship between acculturation and social inclusion, $r(227)=.27,95 \%$ CI [.02 - .49], $p<.01$, as well as job competency and social inclusion, $r(227)=.26,95 \%$ CI $[.01-.48], p<.01$. Thus, H1 was supported. Specifically, as social inclusion increases, acculturation and job competency increase as well.

Table 1

\begin{tabular}{cccccccccc} 
Variable Means, Standard Deviations, Reliability & Coefficients, & and Correlations \\
\hline Variable & $M$ & $S D$ & $\alpha$ & 1 & 2 & 3 & 4 & 5 & 6
\end{tabular}

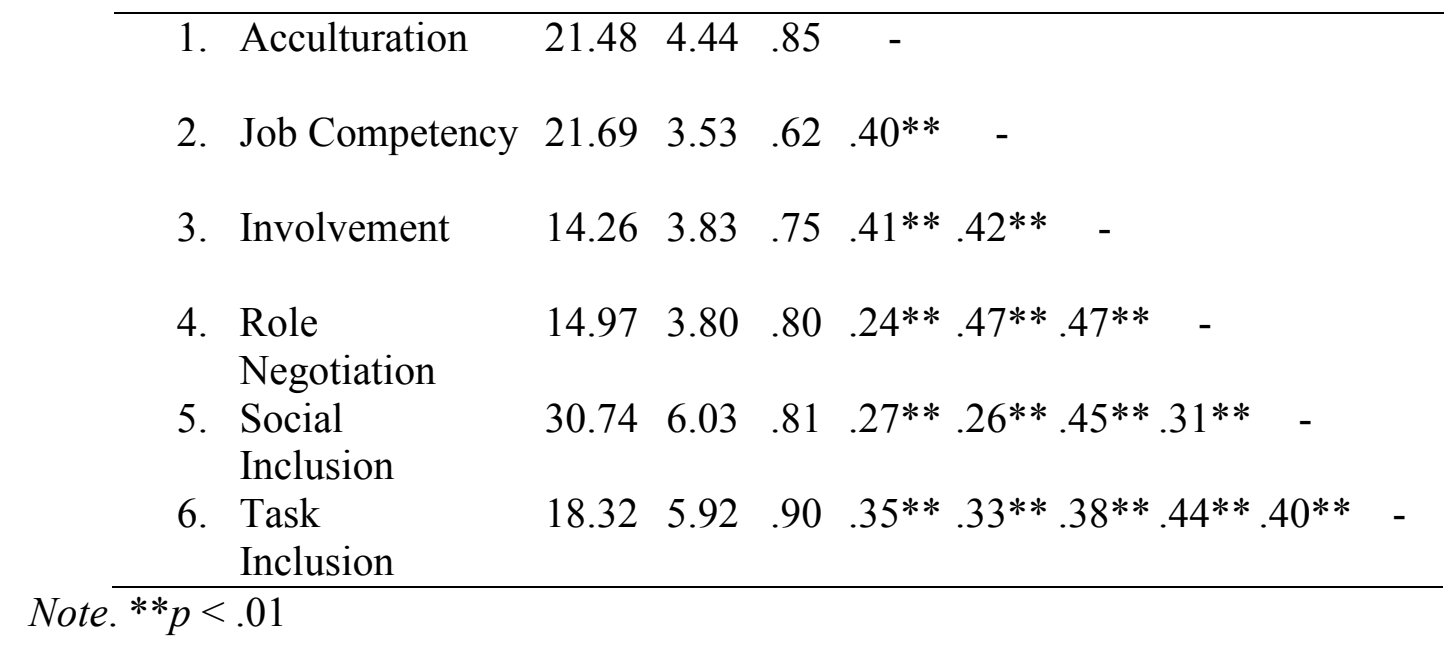


Hypothesis $2 \mathrm{a}$ indicated that task inclusion would also be positively associated with organizational knowledge. Correlation analysis revealed that there was a significant positive relationship between task inclusion and acculturation, $r(227)=.45,95 \%$ CI $[.22$ $-.63], p<.01$, as well as task inclusion and job competency, $r(227)=.31,95 \%$ CI $[.07-$ $.52], p<.01$. Consequently, $\mathrm{H} 2 \mathrm{a}$ received substantial support. Specifically, analyses indicate that increases in task inclusion are associated with increases in both levels of acculturation and job competency.

\section{Inclusion and Individualization}

Hypothesis $1 \mathrm{~b}$ proposed that social inclusion would be positively associated with individualization, which was represented by involvement and role negotiation measures. Correlation analysis revealed that there was a significant positive relationship between involvement and social inclusion, $r(227)=.45,95 \% \mathrm{CI}[.22-.63], p<.01$, as well as role negotiation and social inclusion, $r(227)=.31,95 \% \mathrm{CI}[.07-.52], p<.01$. Thus, this hypothesis was also supported; as social inclusion increases, involvement and role negotiation increase as well.

Hypothesis $2 \mathrm{~b}$ proposed that task inclusion would be associated positively with individualization. Correlation analysis revealed that there was a significant positive relationship between task inclusion and involvement, $r(227)=.37,95 \% \mathrm{CI}[.15-.57], p$ $<.01$, as well as task inclusion and role negotiation, $r(227)=.44,95 \% \mathrm{CI}[.22-.62], p<$ .01. As predicted, as task inclusion increases, involvement and role negotiation increase as well. 


\section{Social Inclusion and Task Inclusion}

Finally, this study inquired as to whether social or task inclusion would be a bigger predictor of organizational knowledge (RQ1a) and/or individualization (RQ1b). In order to inspect this research question, confidence intervals were calculated for and compared to each of the correlation coefficients in question. Correlation coefficients, as well as confidence intervals can be found in Table 2 .

In obtaining the required confidence intervals, Pearson's $r$ correlation coefficients were first standardized to Fischer z', which were used subsequently to calculate the upper and lower limits of the respective $95 \%$ confidence interval. Interval scores were then converted back to Pearson's $r$ in order to compare each confidence interval's range (see Table 2).

Table 2

Confidence Intervals

\begin{tabular}{ccccc}
\hline Variable & $\begin{array}{c}r-\text { Social } \\
\text { Inclusion }\end{array}$ & $\begin{array}{c}\text { Social } \\
\text { Inclusion } \\
95 \% \mathrm{CI}\end{array}$ & $\begin{array}{c}r-\text { Task } \\
\text { Inclusion }\end{array}$ & $\begin{array}{c}\text { Task } \\
\text { Inclusion } \\
95 \% \mathrm{CI}\end{array}$ \\
\hline Acculturation & $.27^{* *}$ & {$[.02-.49]$} & $.35^{* *}$ & {$[.11-.55]$} \\
$\begin{array}{c}\text { Job } \\
\text { Competency }\end{array}$ & $.26^{* *}$ & {$[.01-.48]$} & $.33^{* *}$ & {$[.09-.54]$} \\
Involvement & $.45^{* *}$ & {$[.22-.63]$} & $.38^{* *}$ & {$[.15-.57]$} \\
$\begin{array}{c}\text { Role } \\
\text { Negotiation }\end{array}$ & $.31^{* *}$ & {$[.07-.52]$} & $.44^{* *}$ & {$[.22-.62]$} \\
\hline
\end{tabular}

Note. ${ }^{* * p<.01}$ 
As the statistics found in Table 2 indicate, there was substantial overlap between each of the $95 \%$ confidence intervals being compared. Consequently, the results of this study indicate that the effect sizes were statistically indistinguishable from one another, with regard to their influence on organizational knowledge and individualization. Thus, both social inclusion and task inclusion appear critical to facilitating both types of assimilation outcomes. 


\section{Chapter 5 - Discussion}

Organizational assimilation is an ongoing process that organizational members undergo (Myers \& Oetzel, 2003). Particularly, organizational assimilation occurs when members feel that they both belong to the organization, and are also able to make changes within the organization (Gailliard et al., 2010; Jablin, 2001; Myers, 2009; Waldeck \& Myers, 2007). Organizational members rely on social interactions to guide them in their organizational behavior (Chao et al., 1994; Morrison, 1993; Morrison, 2002). The extent to which organizational members feel they are included, both socially and in tasks, is positively associated with outcomes such as organizational knowledge and individualization. Specifically, the results of this study support that organizational members may rely on social interactions with other organizational members in order to acquire necessary information about how to perform their roles (Cranmer et al., 2017; Korte, 2009; Gailliard et al., 2010; Morrison, 1993; Myers \& McPhee, 2006; Scott \& Myers, 2010), and gauge their behavior against the behavior of others through social feedback (Morrison, 1993; Scott \& Myers, 2010).

In the main, for the organizational members in this study, the more socially included they felt, the more organizational knowledge they displayed through stronger levels of acculturation and through job competency. Thus, social inclusion is important for members in learning how to behave according to the culture of the organization, in addition to the very practical benefit of learning how to perform their jobs. Social inclusion was also positively associated with the individualization of these organizational members. Indeed, as these data show, the more socially included that members felt, the 
more they individualized their roles. This is consistent with Jones's (1986) finding that when organizational members engage in positive social interactions they are more likely to adopt an innovative role orientation. This is because positive social interactions reinforce people's beliefs in their own competency (Jones, 1986), and likely are a source of confidence in the ability to make changes to their role (see also, Perrot et al., 2014).

Similar to social inclusion, task inclusion was positively associated with both organizational knowledge and individualization. Indeed, those that felt included in decision-making processes were more acculturated to the organization and had higher reported levels of job competency. In addition, those who felt included in decisionmaking processes also felt freedom to make changes to their role, which presumably occurred because they were being consulted about specific job-related tasks (Cotton et al., 1988; Miller \& Monge, 1986). These data are consistent with the work of Ding and Shen (2017), which indicates that including employees in decision-making gives members the tools they need in order to create beneficial changes to their roles and socialize to the organization. Indeed, these findings suggest that a direct result of discussing task-based information with others allows employees to make use of their unique skills and abilities when attempting to improve efficiency and alter their role in the workplace (Haueter, Hoff Macan, \& Winter, 2003).

Finally, the results of this study indicate that both forms of inclusion were critical to facilitating levels of acculturation, job competency, involvement, and role negotiation. Indeed, the results of this study suggest that inclusion in both social interactions, and in tasks through participatory decision-making, may be a worthy pursuit in influencing 
assimilation outcomes. Ultimately, these results are important because they indicate that different types of inclusion are essential (Ferdman, 2014; Mor-Barak \& Cherin, 1998) and could provide reason for corporations to create an inclusive atmosphere and culture in order to create conditions for employees to assimilate to the organization. By incorporating and formalizing practices that create conditions where employees feel included, employers may also be directly influencing the extent to which their employees will assimilate to the organization and other assimilation outcomes such as lower turnover rates, increased job satisfaction (Cranmer et al., 2017) and organizational identification (Myers \& Oetzel, 2003).

Ultimately, these results are encouraging, as assimilation is important for employees because it allows them to engage in a dynamic relationship with their organization (Myers \& Oetzel, 2003). This dynamic relationship allows members to conform to the organization, feel involved, but also attempt to define their role and influence the organization (Waldeck \& Myers, 2007). This dynamic relationship could create more efficiency for organizations because employees are taking action to create more efficiency in their roles or the organization at large. In addition to efficiency, assimilation could also create more invested and satisfied employees as members are permitted to employ their unique skills and abilities in their role (Jablin, 2001).

The results of this study are also useful to the field of assimilation research as those who participated in the study occupied many different roles within the organization, and many of the participants were not newcomers, but had been an organizational member for some time. Assimilation research has been critiqued for focusing too heavily 
on newcomer experiences (Myers \& Oetzel, 2003), yet assimilation is an ongoing process that can be ignited by organizational change and turbulence (Chao et al., 1994; Gailliard et al., 2010; Myers \& Oetzel, 2003). Thus, these findings are insightful to assimilation for employees in many different kinds of roles and at different stages of their organizational membership.

\section{Limitations and Directions for Future Research}

As a general limitation, due to recruitment strategies for this survey and the reliance on department chairs to forward the link via email to their departments, some departments were represented while others were not. Furthermore, it is possible that department chairs who were interested in the study at hand may have been more likely to forward the link to their staff, while others may not have forwarded the link. This is important to consider because department chairs that did not forward the link may oversee a department with a less inclusive atmosphere, and thus could have restricted this valuable data and perspective. This could potentially be rectified by contacting survey participants directly, rather than relying on department chairs to be the conduit of survey recruitment. This could also be rectified by collecting data in other settings and samples to determine whether the results found here replicate.

Another limitation is the nature of analysis of this study, wherein the causal nature of these organizational components remains unclear. This could be addressed with a longitudinal research design, wherein the causality of the relationship between these components could be explored. In addition, a longitudinal study could investigate how these experiences may change over the course of membership for employees. 
Of note, all of the constructs measured in this study were moderately correlated with one another. This is to be expected for organizational knowledge and individualization, as they are two components of the same overall construct of organizational assimilation. In order to be assimilated, organizational members should report both familiarity with the organization and expected behavioral norms (Gailliard et al., 2010; Waldeck \& Myers, 2007), as well as attempts made to change some aspect of their role or organizational process (Gailliard et al., 2010; Jablin, 2001). However, the moderate correlation of the assimilation constructs with inclusion reported in this study may cause concern that these constructs may not be distinct from one another, and require further analysis in future research to confirm that they are indeed distinct constructs. Future research can address this with confirmatory factor analysis (e.g., see Hunter \& Gerbing, 1982; Manata, Miller, Mollaoglu, \& Garcia, 2018). Moreover, it should be noted that extant literature both conceptualizes and operationalizes the constructs of organizational assimilation and inclusion differently.

Additionally, the scale used to measure job competency reported a low reliability for this study. This could be addressed by adding items to the scale to improve the consistency of the measure (e.g., see Nunnally, Bernstein, \& Berge, 1967), or by supplementing a scale that has been validated by other research and reports a higher reliability than the scale used in this study.

Furthermore, this study was conducted with the employee population of a university in the Pacific Northwest; therefore, these results may not necessarily be generalized to other types of industry or work settings. The culture of a university as an 
institution of learning and acceptance may not be the case for another type of organization, such as that of a retailer or other type of corporate business. As an example, faculty members are responsible for specific course outcomes, yet how they accomplish these outcomes generally rests with the faculty member. In other words, there may be more freedom for faculty members to make changes to their role as a teacher based on their individual strengths, teaching preferences, and pedagogy. This may not be the case for those in roles with more fixed expectations or tasks (e.g., factory-line worker). Additionally, social inclusion may be difficult for those who telecommute, or do not have much opportunity for interaction with other organizational members. Consequently, future research should further explore different contexts in which task inclusion may be more-or-less applicable. Furthermore, future research should entertain the conditions under which assimilation outcomes are attained despite a lack of social inclusion.

Even in contexts where task inclusion is valued or even formalized through participatory decision-making practices, a perception from employees that they are unable to influence decision-making may neutralize or even undermine the beneficial effects of inclusion. Some of the participants in this study expressed that even though organizational members were given the impression that participatory decision-making was a priority for this organization, they did not perceive that they had any influence. One participant expressed, "Constitutionally, I get a vote in what happens at a departmental level, but a lot of the actual decisions are made at a higher level—we just get to choose how to deal with them, which is a much narrower thing than controlling them. Moreover, just having a vote is nice, but doesn't necessarily mean influence." 
Future research should consider the degree to which organizations are able to facilitate task inclusion, but also how sincere those attempts are and how organizational members at different levels perceive them.

In addition to organizational freedom to make changes or be involved in decisionmaking processes, Ghorpade, Lackritz, and Singh (2006) contend that participatory decision-making requires that employees participate; but not all employees may be inclined to participate. Individual motivation to participate is particularly important for organizations where employee participation is not formal or standardized by the organization (Ghorpade et al., 2006), for example in organizations where employees have a large degree of autonomy and low accountability, or start-up organizations that do not yet have formalized processes. This potential propensity for motivation to participate in formal participative decision-making processes could be another direction for future research to consider. In addition, future research could investigate what motivates individuals to be inclusive of other organizational members. For example, perceived similarity or liking may influence both task and social inclusion (Korte, 2009). Furthermore, inclusion may be more likely in organizations where it is formalized or a part of organizational procedures and culture.

Future research should also attempt to identify specifically how social inclusion may create an atmosphere where organizational members feel able to individualize their roles. For example, Perrot et al. (2014) indicate that perceived organizational support is positively associated with role innovation. Thus, a supportive climate within the organization may create an environment where social inclusion is more likely. Future 
research could then consider the degree to which perceived organizational support influences social inclusion and thus may provide space for employees to individualize or make changes to their role. In contrast, Song, Chathoth, and Chon, (2012) note that participants in their study perceived that those who stood out in some way were punished by their peers, and were disinclined to draw attention to themselves, therefore sacrificing social inclusion due to role innovation. That is to say, depending on group norms, social inclusion may be prioritized over role innovation if role innovation is perceived by the group as negative. As such, perceptions regarding social inclusion, group involvement and acceptance, and expectations regarding role innovation should also be taken into consideration as future scholars explore the association between inclusion and assimilation outcomes. It may be that if group expectations are to maintain the status quo, or that innovation is perceived by the group as negative, members may favor their group membership and social inclusion more so than role innovation.

Finally, future research should attempt to differentiate between the antecedents, mediators, and outcomes of different forms of inclusion (e.g. social, task, etc.) in the interest of assimilation and employees who feel able to influence their role and the organization at large. Research remains unclear "how and why inclusion has beneficial consequences" (Shore et al., 2011, p. 1281), thus antecedents and mediators of inclusion should be explored. However, this study indicates that inclusion is associated with assimilation and the ability to make changes in an organization; however, the casual nature of this relationship remains unclear. Additionally, research indicates that inclusion allows employees to make greater organizational contributions as a result of the value 
and status that inclusion affords organizational members (Shore et al., 2011). Similarly, Haueter et al. (2003) note that task socialization, or acquiring the necessary information about the specific job and tasks one was hired to perform, leads to increased job performance. It seems then that task inclusion, where employees are involved in determining or influencing what their tasks or assignments may be, or how they are completed, might be equally as valuable to job performance. Thus, future research should consider associations of inclusion, knowledge, and job performance.

\section{Conclusion}

Inclusion is a buzzword and has become a popular pursuit of corporations in the last 20 years (Ferdman, 2014). Corporations create formal inclusion initiatives and dedicate departments to providing diversity and inclusion in the workplace (Ferdman, 2014). Yet these attempts at inclusion are not always put into practice and instead are merely used as a way to bolster an organization's reputation in the eyes of the public and to attract desirable employees who might value inclusion (Lunenberg, Gosselt, \& De Jong, 2016). In addition, corporations often lump diversity and inclusion together and consider them as the presence of individuals who may look and think differently. However, the mere representation of different identity groups and cultures does not mean that these individuals will feel included. Inclusion is a necessary component in order to reap the benefits of diversity (Ferdman, 2014). Furthermore, "simply representing a greater variety of differences in an organization or group is not a magical path toward greater performance" (Ferdman, 2014, p. 8). Rather, inclusion occurs within an individual 
when organizations engage, connect with, and utilize individuals across different backgrounds (Ferdman, 2014; Shore et al., 2011).

The results of this study indicate that inclusion, in various forms, is essential to assimilating organizational members. Ultimately, this dynamic relationship is beneficial in that it allows employees to feel that they belong to the organization, but are also unique and able to influence it. Indeed, the results of this study indicate that employees who feel included socially and in tasks are more acculturated to the organization, competent in their roles, more likely to involve themselves in the organization, and negotiate important changes in their roles. As such, organizations should invest in sincere practices and attempts to create environments where employees feel included, so that they may increase their knowledge of organizational culture and practices, and so that they are better able to change their roles (Ferdman, 2014). 


\section{References}

Chao, G. T., O’Leary-Kelly, A. M., Wolf, S., Klein, H. J., \& Gardner, P. D. (1994). Organizational socialization: Its content and consequences. Journal of Applied Psychology, 79(5), 730-743. doi:10.1037/0021-9010.79.5.730

Cotton, J. L., Vollrath, D. A., Froggatt, K. L., Lengnick-Hall, M. L., \& Jennings, K. R. (1988). Employee participation: Diverse forms and different outcomes. The Academy of Management Review, 13(1), 8-22. http://www.jstor.org/stable/258351

Cranmer, G. A., Goldman, Z. W., \& Booth-Butterfield, M. (2017). The mediated relationship between received support and job satisfaction: An initial application of socialization resources theory. Western Journal of Communication, 81(1), 6486. doi:10.1080/10570314.2016.1231931

Ding, C. G., \& Shen, C. (2017). Perceived organizational support, participation in decision making, and perceived insider status for contract workers: A case study. Management Decision, 55(2), 413-426. doi:10.1108/MD-04-2016-0217

Ferdman, B. M. (2014). The practice of inclusion in diverse organizations: Toward a systematic and inclusive framework. In B. M. Ferdman, \& B. R. Deane ( $1^{\text {st }}$ Ed.), Diversity at work: The practice of inclusion, first edition (pp. 2-53). San Francisco, CA: Jossey-Bass.

Gailliard, B. M., Myers, K. K., \& Seibold, D. R. (2010). Organizational assimilation: A multidimensional reconceptualization and measure. Management Communication Quarterly, 24(4), 552-578. doi:10.1177/0893318910374933

Ghorpade, J., Lackritz, J., Singh, G. (2006). Views of employee participation, higher order needs, altruism, pride in craftsmanship, and collectivism: Implications for 
organizational practice and public policy. Journal of Applied Social Psychology, 36(10), 2474-2491. doi: 10.111/j.0021-9029.2006.00113.x

Haueter, J. A., Hoff Macan, T., \& Winter, J. (2003). Measurement of newcomer socialization: Construct validation of a multidimensional scale. Journal of Vocational Behavior, 63(2003), 20-39. doi:10.1016/S0001-8791(02)00017-9

Hunter, J. E., \& Gerbing, D. W. (1982). Unidimensional measurement, second order factor-analysis, and causal-models. Research in Organizational Behavior, 4, $267-$ 299.

Jablin, F. M. (2001). Organizational entry, assimilation, and disengagement/exit. The New Handbook of Organizational Communication. 732-818. Sage: Thousand Oaks, CA. http://dx.doi.org/10.4135/9781412986243

Jones, G. R. (1986). Socialization tactics, self-efficacy, and newcomers' adjustments to organizations. Academy of Management Journal, 29(2), 262-279.

Korte, R. F. (2009). How newcomers learn the social norms of an organization: A case study of the socialization of newly hired engineers. Human Resource Development Quarterly, 20(3), 285-306. doi:10.1002/hrdq.20016

Levine, J. M., Moreland, R. L., (2006). Small groups: Key readings. Psychology Press: New York, NY.

Lunenberg, K., Gosselt, J. F., De Jong, M. D. T. (2016). Framing CSR fit: How corporate social responsibility activities are covered by news media. Public Relations Review, 42(5), 943-951. doi: 10.1016/j.pubrev.2015.11.016 
Manata, B., Miller, V. D., DeAngelis, B. N., \& Paik J. E. (2016). Newcomer socialization research: The importance and application of multilevel theory and communication. Annals of the International Communication Association, 40(1). 307-340. doi:10.1080/23808985.2015.11735264

Manata, B., Miller, V., Mollaoglu, S., \& Garcia, A. J. (2018). Measuring key communication behaviors in integrated project delivery terms. Journal of Management in Engineering, 34(4), 06018001. doi: 10.1061/(ASME)ME.19435479.0000622

Miller, V. D., Johnson, J. R., Hart, Z., Peterson, D. L. (1999). A test of antecedent and outcomes of employee role negotiation ability. Journal of Applied Communication Research, 37(1), 24-48. doi:10.1080/00909889909365522

Miller, K. I., Monge, P.R. (1986). Participation, satisfaction, and productivity: A metaanalytic review. The Academy of Management Journal, 29(4), 727-753. http://www.jstor.org/stable/255942

Morrison, E. W. (1993). Newcomer information seeking: Exploring types, modes, sources and outcomes. Academy of Management Journal, 36(3). 557-589. http://www.jstor.org/stable/256592

Myers, K. K. (2009). Organizational socialization and assimilation. In S. W. Littlejohn \& K. A. Foss, Encyclopedia of Communication Theory (pp. 722-724). Thousand Oaks, CA: Sage. 
Myers, K. K., \& McPhee, R. D. (2006). Influences on member assimilation in workgroups in high-reliability organizations: A multi-level analysis. Human Communication Research, 32, 440-468. doi:10.1111/j.1468-2958.2006.00283.x

Myers, K. K., \& Oetzel, J. G. (2003). Exploring the dimensions of organizational assimilation: Creating and validating a measure. Communication Quarterly, 51(4), 438-457. doi:10.1080/01463370309370166

Nunnally, J. C., Bernstein, I. H., \& Berge, J. M. T. (1967). Psychometric Theory (Vol. 226). New York: McGraw-Hill.

Ostroff, C., \& Kozlowski, S. W. J. (1992). Organizational socialization as a learning process: The role of information acquisition. Personnel Psychology, 45(4), 849874.

Perrot, S., Bauer, T. N., Abonneau, D., Campoy, E., Erdogan, B., \& Liden, R. C. (2014). Organizational socialization tactics and newcomer adjustment: The moderating role of perceived organizational support. Group \& Organization Management, 39(3), 247-273. doi:10.1177/1059601114535469

Scott, C., \& Myers, K. (2010). Toward an integrative theoretical perspective on organizational membership negotiations: Socialization, assimilation, and the duality of structure. Communication Theory, 20(1), 79-105. doi:10.1111/j.14682885.2009.01355.x

Shore, L. M., Randel, A. E., Chung, B. G., Dean, M. A., Ehrhart, K. H., Singh, G. (2011). Inclusion and diversity in work groups: A review and model for future research. Journal of Management, 37(4), 1262-1289. doi:10.1177/0149206310385943 
Song, Z., Chathoth, P. K., \& Chon, K. (2012). Measuring employees' assimilationspecific adjustment. Annals of Tourism Research, 39(4), 1968-1994. doi: 10.1016/j.annals.2012.06.002

Tracey, J. B., \& Hinkin, T. R. (2008). Contextual factors and cost profiles associated with employee turnover. Cornell Hospital Quarterly, 49(1), 12-27. doi: $10.1177 / 0010880407310191$

Training. (2017, November/December). 2017 Training industry report. Retrieved from https://trainingmag.com/trgmag-article/2017-training-industry-report

Waldeck J. H., \& Myers, K. K. (2007). Organizational assimilation theory, research, and implications for multiple areas of the discipline: A state of the art review. Annals of the International Communication Association, 31(1), 322-367. doi:http://dx.doi.org/10.1080/23808985.2007.11679070

Van Maanen, J. \& Schein, E. H. (1979). Toward a theory of organizational socialization. Research in Organizational Behavior, 1, 209-264.

Zorn, T. E., \& Gregory, K. W. (2005). Learning the ropes together: Assimilation and friendship development among first-year male medical students. Health communication, 17(3), 211-231. doi:10.1207/s15327027hc1703_1 


\section{Appendix A. Survey Instrument}

Inclusion/Assimilation Survey Instrument

Informed Consent Form

You are being invited to participate in a research study about inclusion in the workplace. This study is being conducted by graduate student Marisa Miller, from the Department of Communication at Portland State University under the guidance of Dr. Brian Manata.

\section{Procedures}

If you decide to participate, you will be asked to complete the following questionnaire. The questionnaire will take approximately 10 minutes or less.

\section{Risks/Discomforts}

Risks are minimal for involvement in this study. However, you may feel uncomfortable when asked to share information about your work experiences. You are welcome to skip any question that you feel uncomfortable answering.

\section{Benefits}

You may not receive any direct benefit from taking part in this study. However, it is hoped that through your participation, the study may help to increase knowledge which may help others in the future.

\section{Confidentiality}

All information that is obtained in connection with this study will be kept confidential and will only be reported in an aggregate format (by reporting only combined results and never reporting individual ones). All questionnaires will be concealed, and no one other than the research team will have access to them. At no point will you name be linked to your answers.

\section{Compensation}

You may be entered in a drawing to win one of four $\$ 50$ Amazon gift cards in exchange for your participation in this survey. Follow the directions at the end of the survey to submit your preferred email address. This email address with not be linked to your survey answers and is collected only so that you will be entered into the drawing to win a gift card.

\section{Participation}

Participation in this research study is completely voluntary. By completing this survey, you are voluntarily agreeing to participate. You are free to decline to answer any particular question you do not wish to answer for any reason, and you have the right to withdraw at any time or refuse to participate entirely, and it will not affect you in any manner.

\section{Questions about the Research}

If you have any questions about the study, please contact Marisa Miller, gmarisa@pdx.edu, or Dr. Brian Manata, manata@pdx.edu, (503) 725-2284, Portland State University, Department of Communication, PO Box 751, Mailstop SP-COMM, Portland, OR 97207. 


\section{Questions about your Rights as Research Participants}

If you have questions or concerns about your rights as a research subject, please contact the PSU Office of Research Integrity, Market Center Building 6th floor, Portland State University, (503) 7252227. By completing this survey, you are certifying that you are 18 years of age or older, that you have read and understand the above information and agree to take part in the survey.

If at this point you choose to continue in this research study, please click ">>>" to continue.

What is your employment status at the University?

o Full-time employee

0 Part-time employee

- On leave but will return to my position at the University

0 Prefer not to say

- I am not employed by the University 


\section{Organizational Knowledge}

Please indicate your level of agreement with the following statements regarding your employment at the University.

1) I understand the standards of the organization.

$\begin{array}{lllllllll}\text { Strongly Disagree } & 1 & 2 & 3 & 4 & 5 & 6 & 7 & \text { Strongly Agree }\end{array}$

2) I think I have a good idea about how this organization operates.

$\begin{array}{lllllllll}\text { Strongly Disagree } & 1 & 2 & 3 & 4 & 5 & 6 & 7 & \text { Strongly Agree }\end{array}$

3) I know the values of my organization.

$\begin{array}{lllllllll}\text { Strongly Disagree } & 1 & 2 & 3 & 4 & 5 & 6 & 7 & \text { Strongly Agree }\end{array}$

4) I do not mind being asked to perform my work according to the organization's standards.

$\begin{array}{lllllllll}\text { Strongly Disagree } & 1 & 2 & 3 & 4 & 5 & 6 & 7 & \text { Strongly Agree }\end{array}$

5) I can do others' jobs, if I am needed.

$\begin{array}{lllllllll}\text { Strongly Disagree } & 1 & 2 & 3 & 4 & 5 & 6 & 7 & \text { Strongly Agree }\end{array}$

6) I have figured out efficient ways to do my work.

$\begin{array}{lllllllll}\text { Strongly Disagree } & 1 & 2 & 3 & 4 & 5 & 6 & 7 & \text { Strongly Agree }\end{array}$

7) I think I am an expert at what I do.

$\begin{array}{lllllllll}\text { Strongly Disagree } & 1 & 2 & 3 & 4 & 5 & 6 & 7 & \text { Strongly Agree }\end{array}$

8) I often show others how to perform our work.

$\begin{array}{lllllllll}\text { Strongly Disagree } & 1 & 2 & 3 & 4 & 5 & 6 & 7 & \text { Strongly Agree }\end{array}$ 


\section{Individualization}

Please indicate your level of agreement with the following statements regarding your specific job at the University.

9) I volunteer for duties that benefit the organization.

$\begin{array}{lllllllll}\text { Strongly Disagree } & 1 & 2 & 3 & 4 & 5 & 6 & 7 & \text { Strongly Agree }\end{array}$

10) I talk about how much I enjoy my work.

$\begin{array}{lllllllll}\text { Strongly Disagree } & 1 & 2 & 3 & 4 & 5 & 6 & 7 & \text { Strongly Agree }\end{array}$

11) I have helped to change the duties of my position.

$\begin{array}{lllllllll}\text { Strongly Disagree } & 1 & 2 & 3 & 4 & 5 & 6 & 7 & \text { Strongly Agree }\end{array}$

12) I talk to my coworkers about how much I like it here.

$\begin{array}{lllllllll}\text { Strongly Disagree } & 1 & 2 & 3 & 4 & 5 & 6 & 7 & \text { Strongly Agree }\end{array}$

13) I have changed some aspect of my position.

$\begin{array}{lllllllll}\text { Strongly Disagree } & 1 & 2 & 3 & 4 & 5 & 6 & 7 & \text { Strongly Agree }\end{array}$

14) I do this job a bit differently than my predecessor did.

$\begin{array}{lllllllll}\text { Strongly Disagree } & 1 & 2 & 3 & 4 & 5 & 6 & 7 & \text { Strongly Agree }\end{array}$




\section{Social Inclusion}

Please indicate your level of agreement with the following statements regarding your work group/department at the University.

15) Within my work group, I would be easily identified as 'one of the gang'.

$\begin{array}{lllllllll}\text { Strongly Disagree } & 1 & 2 & 3 & 4 & 5 & 6 & 7 & \text { Strongly Agree }\end{array}$

16) I am usually excluded in social get togethers given by other people in my department.

$\begin{array}{lllllllll}\text { Strongly Disagree } & 1 & 2 & 3 & 4 & 5 & 6 & 7 & \text { Strongly Agree }\end{array}$

17) I do not consider any of my coworkers as friends.

$\begin{array}{lllllllll}\text { Strongly Disagree } & 1 & 2 & 3 & 4 & 5 & 6 & 7 & \text { Strongly Agree }\end{array}$

18) I am usually excluded in informal networks or gatherings of people in my department.

$\begin{array}{lllllllll}\text { Strongly Disagree } & 1 & 2 & 3 & 4 & 5 & 6 & 7 & \text { Strongly Agree }\end{array}$

19) I am pretty popular in my department.

$\begin{array}{lllllllll}\text { Strongly Disagree } & 1 & 2 & 3 & 4 & 5 & 6 & 7 & \text { Strongly Agree }\end{array}$

20) I believe most of my coworkers like me.

$\begin{array}{lllllllll}\text { Strongly Disagree } & 1 & 2 & 3 & 4 & 5 & 6 & 7 & \text { Strongly Agree }\end{array}$




\section{Task Inclusion}

Please indicate your level of agreement with the following statements regarding your work.

21) I am able to influence departmental decisions.

$\begin{array}{lllllllll}\text { Strongly Disagree } & 1 & 2 & 3 & 4 & 5 & 6 & 7 & \text { Strongly Agree }\end{array}$

22) I am able to influence work assignment directions.

$\begin{array}{lllllllll}\text { Strongly Disagree } & 1 & 2 & 3 & 4 & 5 & 6 & 7 & \text { Strongly Agree }\end{array}$

23) I am consulted about important project decisions.

$\begin{array}{lllllllll}\text { Strongly Disagree } & 1 & 2 & 3 & 4 & 5 & 6 & 7 & \text { Strongly Agree }\end{array}$

24) I have a say in the way work is performed.

$\begin{array}{lllllllll}\text { Strongly Disagree } & 1 & 2 & 3 & 4 & 5 & 6 & 7 & \text { Strongly Agree }\end{array}$

This is the final page.

Please select your gender.
o Male
o Female
o Other

Please select your ethnicity.

- Asian/Pacific Islander

- Black or African American

- Hispanic or Latino

- White/Caucasian

o Other 
Please select the year you were born.

Please select your department.

Please select your position in your department.

- Advising

- Graduate student worker

0 Faculty

- Office staff

- Undergraduate student worker

- If not listed, please indicate your position here:

- Prefer not to answer

Please enter the amount of time you have been employed by the University (in years).

Is there anything else on this topic that you would like to share? 
Appendix B. Human Subjects Approval

\title{
\& Portland State
}

\begin{abstract}
Post Office Box $751 \quad 503-725-2227$ tel
Portland, Oregon 97207-0751 503-725-8170 fax

Research Integrity (Research a Strategic Partnerships)

IRB (Human Subjects Research Review Committee)

hsrrespla.edu
\end{abstract}

Date: January 24,2018

To: Brian Manata / Marisa Miller, Communication

From: Lindsey Wilkinson, IRB Chair

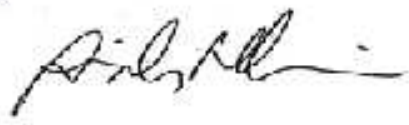

Re: IRB approval for your protocol \# 184479, entitled: "Inclusion and Assimilation in the Workplace"

Approval-Expiration: January 24, 2018 - January 23, 2019

Notice of IRB Review and Approval - Initial Reriew
Expedited Review Category 7; as per Title 45 CFR Part 46

In accordance with your request, the PSU Institutional Review Board (Human Subjects Research Review Committee) has reviewed and approved the project referenced above for compliance with PSU policies and DHHS regulations covering the protection of human subjects. The $\mathbb{R} B$ is satisfied that your provisions for protecting the rights and welfare of all subjects participating in the research are adequate. Please note the following requirements:

Approval: You are approved to conduct this research study only duning the period of approval cited above, and the research must be conducted according to the plans and protocol submitted (approved copy enclosed).

Consent: You must use IRB-approved consent materials with study participants. Signed consent is waived - a written consent statement is required.

Changes to Protocol: Any changes in the proposed study, whether to procedures, survey instruments, consent forms or cover letters, must be outlined and submitted to the IRB immediately. The proposed changes cannot be implemented before they have been reviewed and approved by the IRB.

Continuing Review: This approval will expire on 01/23/2019. It is the investigator's responsibility to ensure that a Continuing Review Report is submitted to the IRB two months before the expiration date, and that approval of the study is kept current. The Continuing Review Report is available on the Research Integnity website.

Adverse Reactions and/or Unanticipated Problems: If any adverse reactions or unanticipated problems occur as a result of this study, you are required to notify the Research Integrity within 5 days of the event. If the issue is serious, approval may be withdrawn pending an investigation by the $\mathbb{R} B$.

Completion of Study: Please notify the IRB as soon as your research has been completed. Study records, including protocols and signed consent forms for each participant, must be kept by the investigator in a secure location for three years following completion of the study (or per any requirements specified by the project's funding agency).

If you have questions or concems, please contact the Research Integity office in Research \& Strategic Partnerships at hnre apdx.edn or (503) 725-2227. 